\title{
Bloodletting and the management of localized prostate cancer
}

\author{
J. Curtis Nickel, MD, FRCSC
}

Professor of Urology, Queen's University, CIHR Tier One Canada Research Chair in Urology, Kingston General Hospital, Kingston, ON

Cite as: Can Urol Assoc J 2011;5(3):159-60; D01:10.5489/cuaj.11076

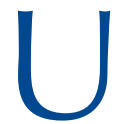
$p$ to 150 years ago, one of the most accepted therapies for maladies of all kinds, including deadly tumours, was bloodletting. ${ }^{1}$ Multiple observations from respected clinicians and medical centres unequivocally showed that most sick patients survived after a simple bloodletting. ${ }^{2}$ It soon became a standard therapy that few clinicians would question, especially since physicians had few procedures to use for many of the illnesses of the day; they all agreed that they could not just do nothing and hope the patient could live without intervention. The clinical scientists soon figured out that they could not save all their patients with bloodletting; they learned that patients who did the best were those who were the healthiest and had the less severe disease characteristics. ${ }^{1-3}$ Controversy, however, raged between physicians and learned clinical centre, with others believing that in severe cases, abundant bloodletting appeared to work better than local bleeding. ${ }^{4}$ The duration of disease was on average shorter in those who had been bled early compared to those bled late. ${ }^{4}$ However, it became apparent that more patients who had early bloodletting died compared to those bled late. The debate, which seemed endless, concerned ideal patient selection, as well as perfecting the timing, the rate, the volume, the frequency and even the location of the procedure. ${ }^{3}$ To decrease morbidity, physicians were encouraged to use a "nerve sparing" approach to venesection. ${ }^{5}$ Although relatively safe, clinician scientists developed better "minimally invasive" ways to bloodlet ("cupping" vs. "lancing"), and although not as simple or less expensive, it seemed to provide the same benefit with less scarring and earlier recovery. ${ }^{6}$ Patients flocked to physicians who appeared to be on the cutting edge in the art, science and technology of bloodletting.

However, a newer generation of clinicians began to question some of the practices of their teachers and even, to the horror and consternation of their older colleagues, wonder if bloodletting was really curing the right patients. ${ }^{7}$ Some of this younger generation of evidence-seeking physicians started reporting that patients who did not undergo the procedure did as well as those who underwent the procedure. ${ }^{8,9}$ But the older respected physicians who staked their career and reputations on bloodletting continued to insist on the benefits of this most traditional of all interventional therapies. ${ }^{10}$ Bitter disagreements and debates ensued about the proper relationship between tradition, experience, empirical observation and the clinical sciences in regard to bloodletting. ${ }^{11}$ Traditionalists firmly believed that results obtained by analyses of large groups of patients were not universally applicable to the single individual presenting in their examining room. ${ }^{12}$ The popularity of bloodletting started to decline when it was unequivocally shown that patients who had the procedure may have been harmed by it, had a slower recovery, poorer quality of life and even hastened the death of some patients who would normally have been expected to live. ${ }^{13,14} \mathrm{~A}$ number of respected physicians, including William Osler in his 1892 "The Principles and Practice of Medicine," believed the medical profession was too hasty to abandon bloodletting and remained an advocate for selected patients, particularly young healthy patients with early disease. ${ }^{15}$ Despite being defended by some leading clinicians, bloodletting disappeared from medical practice when newer, less intrusive and more in vogue treatments (pharmaceutical concoctions based on arsenic and lead ingredients) became the latest therapeutic trend. Bloodletting, once absolutely believed to be the optimal medical/surgical procedure in terms of its perceived benefits versus it known risks, is now only a footnote in history.

If you are asking yourself, what does this article have to do with the early management of prostate cancer, please reread this commentary with an open mind. Future generations of physicians will judge us by how we approach the observations, science and paradoxes that now confront us as we decide to do more good than harm for patients we are 
diagnosing and treating with localized prostate cancer. Let us hope that our present strategy of prostate cancer screening and management is looked on more kindly by history than it did with our bloodletting predecessors.

Competing interests: Dr. Nickel advocates PSA screening for selected men (case selection) in his clinic and performs radical prostatectomy in prostate cancer patients in whom he believes (a bestevidence based approach), it will make a difference. He wants his oncology colleagues to reassure him that years from now his endeavors will have resulted in providing more benefit than harm and not be relegated to the same historic wastebasket as those of his bloodletting ancestors.

This paper has been peer-reviewed.

\section{References}

1. Garrison FH. An introduction to the history of medicine. Philadelphia, PA: WB Saunders Co; 1914.

2. Wardrop T. On Bloodletting. An account of the curative effects of the abstraction of blood: with rules for employing both local and general bloodletting in the treatment of diseases. London, UK: Bailliere; 1835.
3. Perry H. Observations on bloodletting. London Med Reps 1822;17:113-5.

4. Louis PCA. Researches on the effects of bloodletting in some inflammatory diseases. Boston, MA: Hilliard, Gray; 1836.

5. Pelczar ME. Vascular access: an historical review. Asepsis 3"d Quarter 1996;18:9-13.

6. Howard H. Howard's domestic medicine. Philadelphia, PA: Hubbard Brothers; 1879.

7. King LS. The bloodletting controversy: A study in the scientific method. Bull Hist Med 1961;35:1-13.

8. Niebyl PH. The English bloodletting revolution, or modern medicine before 1850. Bull Hist Med 1977; 51:464-83.

9. Hosgood G. Bloodletting: the old and the new. J Am Vet Med Assoc 1991;198:238-9.

10. Hoff JW. Blood-letting as a therapeutic remedy based on a report of twenty-six cases. JAMA 1897;29:424427, 1897.

11. Warner JH. Papers from a symposium held in the Royal College of Physicians of Edinburgh on $27^{\text {th }}$ September 1995. Proceedings of the Royal College of Physicians and Surgeons of Edinburg 1995;27 (Suppl.3):22-31.

12. Van Gijn J. The power of numbers. Ned Tijdschr Geneeskd 2000;144:1-3.

13. Watson Sir Thomas. Lectures on principles and practice of physic. London, UK: JW Parker; 1843.

14. DePalma RG, Hayes VW, Zacharski LR. Bloodletting: Past and Present. J Am Coll Surg 2007;205:132-44.

15. Osler W. The principles and practice of medicine: designed for the use of practitioners and students of medicine (1892). Birmingham: Classics of Medicine Library; 1978.

Correspondence: Dr. J. Curtis Nickel, Kingston General Hospital, Department of Urology, 76 Stuart St., Kingston, 0N K7L 2V7; fax: 613-545-1970; jin@queensu.ca 